\title{
Crosstalk between MicroRNAs and Peroxisome Proliferator-Activated Receptors and Their Emerging Regulatory Roles in Cardiovascular Pathophysiology
}

\author{
Yin-Feng Zhang $\mathbb{D}^{1},{ }^{1}$ Hai-Ming Xu, ${ }^{2}$ Fei Yu, ${ }^{1}$ Man Wang, ${ }^{1}$ Meng-Yang Li, ${ }^{1}$ Tao Xu, \\ Yan-Yan Gao, ${ }^{1}$ Jian-Xun Wang, ${ }^{1}$ and Pei-Feng $L i \mathbb{D}^{1}$ \\ ${ }^{1}$ Institute for Translational Medicine, College of Medicine, Qingdao University, Deng Zhou Road 38, Qingdao 266021, China \\ ${ }^{2}$ Department of Occupational and Environmental Medicine, School of Public Health and Management, Ningxia Medical University, \\ Yinchuan, Ningxia Hui Autonomous Region, China \\ Correspondence should be addressed to Yin-Feng Zhang; zhangyinfeng@qdu.edu.cn and Pei-Feng Li; peifli@qdu.edu.cn
}

Received 12 September 2018; Revised 31 October 2018; Accepted 27 November 2018; Published 5 December 2018

Academic Editor: Stéphane Mandard

Copyright (C) 2018 Yin-Feng Zhang et al. This is an open access article distributed under the Creative Commons Attribution License, which permits unrestricted use, distribution, and reproduction in any medium, provided the original work is properly cited.

\begin{abstract}
Peroxisome proliferator-activated receptors (PPARs) play vital roles in cardiovascular pathophysiology, such as energy balance, cell proliferation/apoptosis, inflammatory response, and adipocyte differentiation. These vital roles make PPARs potential targets for therapeutic prevention of cardiovascular diseases (CVDs). Emerging evidence indicates that the crosstalk of microRNAs (miRNAs) and PPARs contributes greatly to CVD pathogenesis. PPARs are inhibited by miRNAs at posttranscriptional mechanisms in the progress of pulmonary hypertension and vascular dysfunction involving cell proliferation/apoptosis, communication, and normal function of endothelial cells and vascular smooth muscle cells. In the development of atherosclerosis and stroke, the activation of PPARs could change the transcripts of target miRNA through miRNA signalling. Furthermore, the mutual regulation of PPARs and miRNAs involves cell proliferation/apoptosis, cardiac remodeling, and dysfunction in heart diseases. In addition, obesity, an important cardiovascular risk, is modulated by the regulatory axis of PPARs/miRNAs, including adipogenesis, adipocyte dysfunction, insulin resistance, and macrophage polarization in adipose tissue. In this review, the crosstalk of PPARs and miRNAs and their emerging regulatory roles are summarized in the context of CVDs and risks. This provides an understanding of the underlying mechanism of the biological process related to CVD pathophysiology involving the interaction of PPARs and miRNAs and will lead to the development of PPARs/miRNAs as effective anti-CVD medications.
\end{abstract}

\section{Introduction}

Peroxisome proliferator-activated receptors (PPARs) belong to the family of ligand-activated nuclear hormone receptors, and they serve as important regulators in many physiological processes, including modulation of the metabolism of carbohydrates, lipids, and proteins; cellular proliferation and differentiation; inflammation; and tumorigenesis [1]. PPARs heterodimerize with the retinoid $\mathrm{X}$ receptor and subsequently bind to peroxisome proliferator response elements (PPREs) in the DNA of target genes [2]. PPARs include three isoforms-PPAR $\alpha, \operatorname{PPAR} \beta / \delta$, and PPAR- $\gamma$-that present many different features such as ligand specificities, tissue distribution, coactivators or corepressors specificities, and effects [3]. Emerging evidence has demonstrated that PPARs have a wide range of biological activities that prevent and treat CVDs [4]. Moreover, the availability of natural and synthetic small molecule agonists, many of which are relatively wellstudied, makes PPARs attractive therapeutic targets $[5,6]$.

1.1. Cardiovascular Diseases (CVDs). Cardiovascular diseases (CVDs) are the leading cause of death all over the world. Atherosclerosis (ATH), hypertension, myocardial infarction, and cerebrovascular disease (stroke) are the most common CVDs that involve the heart and blood vessels [7-9]. Heart failure (HF) causes the most deaths worldwide and is usually associated with cardiac hypertrophy and cardiomyocyte apoptosis [10]. Obesity, a worldwide 
TABLE 1: The beneficial effects of peroxisome proliferator-activated receptors (PPARs) activation on cardiovascular diseases and risks.

\begin{tabular}{|c|c|c|c|c|}
\hline Diseases & Cell & $\operatorname{PPAR} \alpha$ & $\operatorname{PPAR} \beta / \delta$ & PPAR $\gamma$ \\
\hline \multirow{3}{*}{ Vessel wall } & Endothelial cell & $\begin{array}{l}\text { Nitric oxide release } \uparrow \\
\text { Inflammation } \downarrow\end{array}$ & $\begin{array}{c}\text { Nitric oxide release } \uparrow \\
\text { Proliferation } \uparrow \\
\text { Apoptosis } \downarrow \\
\text { Inflammation } \downarrow\end{array}$ & $\begin{array}{c}\text { Apoptosis } \downarrow \\
\text { Reactive oxygen } \\
\text { species } \downarrow \\
\text { Inflammation } \downarrow\end{array}$ \\
\hline & $\begin{array}{l}\text { Vascular smooth } \\
\text { muscle cell }\end{array}$ & $\begin{array}{c}\text { Apoptosis } \uparrow \\
\text { Proliferation } \downarrow \\
\text { Migration } \downarrow \\
\text { Inflammation } \downarrow\end{array}$ & $\begin{array}{c}\text { Proliferation } \downarrow \\
\text { Migration } \downarrow \\
\text { Apoptosis } \downarrow\end{array}$ & $\begin{array}{c}\text { Proliferation } \downarrow \\
\text { Migration } \downarrow \\
\text { Apoptosis } \downarrow\end{array}$ \\
\hline & $\begin{array}{l}\text { Monocyte/ } \\
\text { Macrophage }\end{array}$ & $\begin{array}{c}\text { Inflammation } \downarrow \\
\text { Lipid accumulation } \downarrow \\
\text { Reverse cholesterol } \\
\text { transport } \uparrow\end{array}$ & $\begin{array}{c}\text { Lipid/cholesterol } \\
\text { metabolism } \uparrow \\
\text { Inflammation } \downarrow\end{array}$ & $\begin{array}{c}\text { Reactive oxygen } \\
\text { species } \downarrow \\
\text { Nitric oxide synthase } \\
\uparrow \\
\text { Reverse cholesterol } \\
\text { transport } \uparrow\end{array}$ \\
\hline Heart & Cardiomyocyte & $\begin{array}{c}\text { Fatty acid } \\
\text { metabolism } \uparrow \\
\text { Glucose uptake and } \\
\text { oxidation } \downarrow\end{array}$ & $\begin{array}{c}\text { Proliferation } \uparrow \\
\text { Energy balance } \uparrow \\
\text { Metabolic } \\
\text { modulation } \uparrow\end{array}$ & Inflammation $\downarrow$ \\
\hline Risk factors & Adipocyte & $\begin{array}{c}\text { Adipocyte } \\
\text { differentiation } \uparrow \\
\text { Lipolysis } \uparrow \\
\text { Fatty acid oxidation } \\
\uparrow\end{array}$ & $\begin{array}{c}\text { Adipocyte } \\
\text { differentiation } \uparrow \\
\text { Fatty acid } \\
\text { metabolism } \uparrow\end{array}$ & $\begin{array}{c}\text { Adipocyte } \\
\text { differentiation } \uparrow \\
\text { Lipolysis } \uparrow\end{array}$ \\
\hline
\end{tabular}

epidemic, is an important risk factor for CVDs [11]. This inflammatory condition is caused by both adipocyte hypertrophy and adipogenesis.

ATH is a complicated vascular disease that can be ascribed to many factors $[7,12]$. In the development of ATH, the proliferation of vascular smooth muscle cells (VSMCs) and damage to endothelial cell (ECs) resulting in the expression of adhesion molecules and leukocyte adhesion are important events $[13,14]$. Additionally, accumulation of lowdensity lipoproteins, monocytes, and macrophages constitutes a plaque in the vascular wall. When the atherosclerotic plaque builds and becomes fragile, it can rupture, causing a variety of leading death diseases, such as stroke and myocardial infarction [15].

Pulmonary hypertension (PH) is an enigmatic vascular disorder driven by disparate triggers such as inflammation and hypoxia, and it results in significant morbidity and mortality [16]. Development of $\mathrm{PH}$ involves various molecular pathways that include several cell types especially pulmonary arterial smooth muscle cells (PASMCs) and pulmonary arterial ECs (PAECs) [17].

\subsection{Role of Peroxisome Proliferator-Activated Receptors (PPARs) in CVDs}

1.2.1. PPAR $\alpha$. The first cloned PPAR isotype was $\operatorname{PPAR} \alpha$, which is expressed predominantly in high-energy requiring tissue such as brown adipose tissue and the parenchymal cells of the heart [18-20]. The beneficial effect of PPAR $\alpha$ in the pathogenesis of ATH and management of cardiomyocyte metabolism has been studied extensively [21, 22].
Activation of PPAR $\alpha$ has been demonstrated to raise the plasma levels of atheroprotective high-density lipoprotein cholesterol and reduce circulating levels of triglycerides (TG), free fatty acids (FAs), and apolipoprotein CIII. PPAR $\alpha$ activation has also been shown to improve the overall proatherosclerotic plasma lipid profile and to have beneficial effects on insulin resistance and inflammation [23].

The heart's energy comes predominantly from FA oxidation (FAO), and PPAR $\alpha$ is expressed at a relatively high level in the heart. Moreover, PPAR $\alpha$ agonist treatment could induce the expression of various genes involved in FA utilization, including FA translocation, esterification, and $\beta$ oxidation, and reduce the expression of the genes involved in glucose uptake and use [24] (Table 1).

A relatively high-level expression of PPAR $\alpha$ also occurs in most cell types present in the vasculature, including ECs, VSMCs, monocytes, macrophages, and macrophagerich regions of atherosclerotic regions [25]. In ECs, the activation of PPAR $\alpha$ could interfere with the metabolic processes involved in recruitment of inflammatory cells and regulation of redox responses, which would prevent vascular inflammation and injury $[26,27]$. In addition, $\operatorname{PPAR} \alpha$ agonists increase nitric oxide (NO) production in ECs and induce NO synthase (NOS) expression, suggesting a vasculoprotective effect [23] (Table 1).

Similar to other vascular cells, PPAR $\alpha$ has an antiinflammatory effect in VSMCs. In addition, PPAR $\alpha$ activation can exert inhibition effects on VSMC proliferation and migration mediated by the nuclear factor- $\kappa \mathrm{B}$, transforming growth factor- $\beta /$ Smad, and the mitogen-activated protein kinase (MAPK) pathway. And the activation of PPAR $\alpha$ has 
proapoptotic effects on VSMCs by targeting the p38 MAPK signalling cascade [28] (Table 1).

In macrophages, activation of PPAR $\alpha$ exerts a vasculoprotective effect by attenuating TG accumulation and reducing tissue factor synthesis, matrix metallopeptidase9, and tumour necrosis factor $\alpha$ (TNF- $\alpha$ ) secretion [29]. Moreover, PPAR $\alpha$ helps to relive and stabilize the atherosclerotic plaques through promoting transport of cholesterol and enhancing collagen content [30,31] (Table 1). PPAR $\alpha$ has also been shown to suppress platelet-activating receptor transcription in monocytes [32, 33]. Additionally, PPAR $\alpha$ activation could promote FAO, lipolysis, and adipocyte differentiation in adipocytes and improve insulin resistance without adipocyte lipid accumulation [34] (Table 1).

1.2.2. $P P A R \beta / \delta$. Accumulating evidence has shown the direct effects of PPAR $\beta / \delta$ on cardiovascular processes, such as endothelial function and angiogenesis [3]. PPAR $\beta / \delta$ is highly expressed in vasculature cell types including ECs, VSMCs, and monocyte-macrophages, and it contributes greatly to the function of these cell types $[35,36]$. PPAR $\beta / \delta$ activation coordinates various functions in ECs, including the proliferation of ECs and endothelial progenitor cells, stimulating transcription of antioxidant enzymes, raising the phosphorylation of EC NOS (eNOS) and secretion NO, reducing inflammation and apoptosis, and regulating angiogenesis $[37,38]$ (Table 1). PPAR $\beta / \delta$ also regulates VSMC function through several mechanisms. PPAR $\beta / \delta$ represses VSMC proliferation, migration by sustentation of extra cellular matrix, suppression of apoptosis, and attenuation of senescence through increasing antioxidant enzyme genes and inhibiting inflammation $[39,40]$ (Table 1).

In macrophages, $\mathrm{PPAR} \beta / \delta$ exerts an important role in the modulation of lipid/cholesterol metabolism and inflammatory responses [41]. Additionally, $\operatorname{PPAR} \beta / \delta$ has vital effects on the regulation of brown or white adipose tissue FA transportation, oxidation metabolism, and thermogenesis $[40,42]$. The evidence shows that the proper balance of $\operatorname{PPAR} \beta / \delta$ activation is required to obtain beneficial effects on the outcome in ATH and chronic ischemic heart disease $[37,43,44]$. In the heart, $\operatorname{PPAR} \beta / \delta$ is a crucial regulatory factor of primary myocardial FAO, and it is necessary to coordinate normal cardiac function and energy balance [45] (Table 1).

Usually, heart regeneration in the mammalian heart is limited to newborns [46]. However, Magadum et al. [47] demonstrated that the activation of PPAR $\beta / \delta$ by carbacyclin could promote cardiomyocyte proliferation. PPAR $\beta / \delta$ could also modulate the differentiation of adipocytes both independently and by targeting PPAR $\gamma$. This could regulate FA transportation, oxidation, and thermogenesis in white or brown adipose tissue and help to improve insulin sensitivity (Tanaka et al., 2017) (Table 1).

1.2.3. PPAR $\gamma$. The cardioprotective effect of $\operatorname{PPAR} \gamma$ activation has been studied extensively, and it is considered to be a potential therapeutic target in CVDs [1]. PPAR $\gamma$ is highly expressed in VSMCs, ECs, cardiomyocytes, macrophages, and adipocytes [48]. PPAR $\gamma$ plays a crucial effect in inhibiting apoptosis and oxidative stress and improving endothelial function [49] (Table 1). PPAR $\gamma$ plays a role against the inflammatory response of many cardiovascular cells, specifically ECs [50]. Activation of PPAR $\gamma$ can decrease the expression of factors such as TNF- $\alpha$, resistin, and interleukin 1. PPAR $\gamma$ could also reduce inducible NOS increase and reactive oxygen species generation in macrophages. PPAR $\gamma$ is a primary regulator of adipogenesis, and $\operatorname{PAAR} \gamma$ activation exerts important effects on the regulation of lipid metabolism in adipocytes and glucose homeostasis and adipogenesis in subcutaneous fat $[51,52]$ (Table 1 ).

Most studies have focused on the beneficial role of PPAR $\gamma$ in preventing many cardiovascular disorders, such as insulin resistance [53, 54], ATH [55], hypertension, ischemia/reperfusion (I/R) injury [56], and dyslipidaemia [57]. In addition to regulating plasma lipoprotein concentrations, PPAR $\gamma$ may modulate foam cell formation, affect the inflammatory response, and regulate plaque stability [58]. $\operatorname{PPAR} \gamma$ may also reduce the plasma level of atherogenic proteins. Recently, PPAR $\gamma$ has been shown to exert neuroprotection in stroke both in rodent models and humans, which makes PPAR $\gamma$ activators a potentially ideal treatment for ischemic brain injury $[59,60]$.

In the heart, PPAR $\gamma$ protein expression was only at low to moderate levels. However, PPAR $\gamma$ activation was demonstrated to cause cardiac dysfunction with significant changes in the metabolism of free FA and glucose. The therapeutic effects of PPAR $\gamma$ ligands on cardiomyocytes are predominately attributed to their anti-inflammatory effects (Lee et al., 2015) (Table 1).

Above all, PPARs may have remarkable protective roles in various cell types involving in the pathophysiology of CVDs and could often be considered to be potential targets for therapeutic intervention of CVDs.

1.3. Crosstalk between MicroRNAs (miRNAs) and PPARS in CVDs. MiRNAs are defined as highly conserved endogenous noncoding RNAs, approximately 16-22 nucleotides in length [61]. MiRNAs function primarily by binding to $3^{\prime}$ untranslated regions ( $3^{\prime}$ UTR) of target miRNAs and usually decrease the expression of target genes at the posttranscriptional level [62-64]. MiRNAs are usually generated by a canonical pathway $[65,66]$. The miRNA-loaded, RNA-induced silencing complex can silence the target gene expression by either targeting transcript degradation/decay or suppressing target transcript translation $[13,65]$.

According to the newly developed international genome feature nomenclature guidelines of miRNAs, many rules should be noted such as informing through the annotation without bias [67]. For instance, the unbiased " $5 \mathrm{p} / 3 \mathrm{p}$ " strand annotation is used to replace the " $\mathrm{miR} / \mathrm{miR}^{*}$ " symbolism for deciphering the strand position from the pre-miRNA hairpin independently of its transcription status.

More than 2,000 miRNAs have been identified, and about 45,000 miRNA-targeting positions exist in the human genome, influencing the transcription of about $60 \%$ of genes [68]. MiRNAs can modulate almost all cellular functions and alterations of their expression/activity; this is observed in various pathological conditions, especially in CVDs [69-72]. 
Emerging evidence has suggested the miRNA/PPAR $\gamma$ regulatory axis contributes greatly to CVDs and risk factors. Herein, the regulation of PPARs by miRNAs is reviewed in the context of $\mathrm{PH}$, vascular dysfunction, heart disease, and obesity-associated cardiovascular risks. Reciprocal control of miRNAs expression by PPARs is also discussed. This will advance the understanding of the molecular pathway in CVDs and guide miRNA/PPAR axis-based therapeutic treatment in these diseases.

1.3.1. Pulmonary Hypertension (PH). It has been suggested that the miRNA/PPAR $\gamma$ regulatory axis might contribute greatly to $\mathrm{PH}$ pathogenesis by regulating proliferation/apoptosis, communication, and normal function of PAECs and PASMCs.

The miR-130/301 family was demonstrated as a crucial regulator of PH by targeting PPAR $\gamma$ (Figure 1) [73-75]. The miRNA-130/301 family was upregulated by various stimuli of $\mathrm{PH}$ in both animals and humans. It regulated proliferation and apoptosis of pulmonary vascular cells via inhibition of its target PPAR $\gamma$. The miRNA-130/301-PPAR $\gamma$ axis modulated PAEC proliferation and apoptosis by regulating the signal pathway of apelin-miRNA-424/503-FGF2. For PASMCs, the miR-130/301-PPAR $\gamma$ axis promoted cell proliferation through controlling miRNA-204 and signal transducer and activator of transcription 3 (STAT3) [75]. Furthermore, in murine models, chronic miR-130/301 treatment was necessary and sufficient to induce $\mathrm{PH}$ by targeting $\operatorname{PPAR} \gamma$ and the subordinated miRNA pathways [75]. The molecular crosstalk among various cell types was very important in the progress of PH. Bertero et al. [73] proved that the miR-130/301/PPAR $\gamma$ axis in PAECs regulated various vasoactive factors, most significantly endothelin-1(EDN1), which serves as a vital regulator of vascular communication between PAECs and PASMCs, vasomotor tone, and $\mathrm{PH}$ manifestation in vivo. The miR-130/301-PPAR $\gamma$ axis induced paracrine expression of STAT3 and promoted actinomyosin-dependent contraction of PASMCs by producing EDN1. In addition, the remodeling and stiffening of vascular extracellular matrix (ECM) were early and ordinary processes which aggravated $\mathrm{PH}$. Moreover, Bertero et al. [74] found that miR-130/301 promoted ECM stiffening and further elevated YAP/TAZ through a feedback loop by targeting a PPAR $\gamma$-apolipoprotein E/LRP8 axis. And the suppression of microRNA-130/301 as well as apolipoprotein E by targeting PPAR $\gamma$ signalling could ameliorate ECM remodeling and improve $\mathrm{PH}$ in vivo [74].

The dysfunction of PAECs was closely related to $\mathrm{PH}$. The miRNA-27a/PPAR $\gamma$ axis was confirmed to mediate mutually repressive actions in hypoxic human PAECs and also in vivo (Figure 1) [76]. Hypoxia, a common PH stimulus, increased the lungs' miRNA-27a expression and reduced PPAR $\gamma$ levels, which stimulated increased EDN1 levels and proliferation of pulmonary vascular cells. However, activating PPAR $\gamma$ by rosiglitazone (RSG) could directly reduce hypoxia-induced miRNA-27a transcription and then EDN1 levels, resulting in decreased PAECs proliferation [76].

In rats, miRNA-27b was highly expressed in $\mathrm{PH}$, and inhibition of miRNA-27b attenuated monocrotaline-caused endothelial dysfunction and remodeling and then protected
PH. Further, PPAR $\gamma$ was demonstrated to directly modulate miRNA-27b expression in PAECs. Moreover, the miRNA27a/PPAR $\gamma$ axis regulated Hsp90-eNOS and NO signalling in human PAECs; this signalling was closely associated with the PH phenotype (Figure 1) [77].

MiRNA-21 was confirmed as an important regulator of $\mathrm{PH}$ pathogenesis by its promotion of PASMC proliferation. However, PPAR $\gamma$ activation exerted an antiproliferative role through suppression of hypoxia-induced miRNA-21 transcription. Furthermore, RSG reduced miRNA-21 expression increased by hypoxic treatment both in vitro and in vivo, and it abolished decrease in phosphatase and tensin homolog deleted on chromosome 10 (PTEN) and PASMC proliferation [78]. The antiproliferative effects of RSG disappeared after PTEN depletion. In addition, miRNA-21 mimic reduced PTEN and promoted PASMC proliferation, while miRNA21 suppression raised PTEN and reduced hypoxia-induced human PASMC proliferation (Figure 1) [78]. Green et al. found that the activation of PPAR $\gamma$ could stimulate the central mediator of apoptosis programmed cell death 4 expression, by inhibiting miRNA-21 and promoting PASMC proliferation (Figure 1) [79]. These findings provided critical validation for developing the miRNA/PPAR $\gamma$ axis-based therapeutics for $\mathrm{PH}$.

1.3.2. Vascular Dysfunction. Additionally, this miRNA/PPAR axis could provide novel therapeutic strategies for the treatment of ATH or stroke-related vascular dysfunction. Under conditions of endothelial dysfunction, adhesion of plasma monocytes to vascular ECs is a vital event contributing to vascular inflammation and further induces the development of ATH [80]. The crosstalk between miRNA-21 and $\operatorname{PPAR} \alpha$ was shown to play key roles in proinflammatory molecule transcription and the adhesion of monocytes to ECs (Figure 2) [81]. The oscillatory shear stress induction of miRNA-21 inhibited PPAR $\alpha$ by directly targeting at the $3^{\prime}$ UTRs of PPAR $\alpha$. Therefore, the repressive influence of $\operatorname{PPAR} \alpha$ on the activation of transcription factor activator protein-1 was alleviated. And then, $\operatorname{PPAR} \alpha$ inhibition promoted the transcription of adhesion molecules including vascular cell adhesion molecule-1 and monocyte chemotactic protein-1, finally resulting in EC inflammation (Figure 2) [81]. Moreover, the increase of miRNA-21 transcription further inhibited PPAR $\alpha$ expression from forming a positive feedback circuit.

As is well known, very low-density lipoprotein (VLDL) might enhance the permeability and apoptosis of ECs and increases inflammatory response, playing a crucial role in atherogenesis especially for coronary artery diseases [82]. In ECs, it was shown that the PPAR $\beta / \delta$ activation could inhibit VLDL receptor transcription and VLDL uptake through directly regulating miRNA-100, suggesting a vasculoprotective effect (Figure 2) [83].

Furthermore, the activation of $\operatorname{PPAR} \beta / \delta$ or $\operatorname{PPAR} \gamma$ directly suppresses the transcriptional levels of proapoptotic miRNA-15a, playing a potential neuroprotective effect for ischemic stroke (Figure 2) [84]. The degeneration of cerebral vascular endothelial cells (CECs) is obviously related to blood-brain barrier breakdown as well as neuronal loss after 


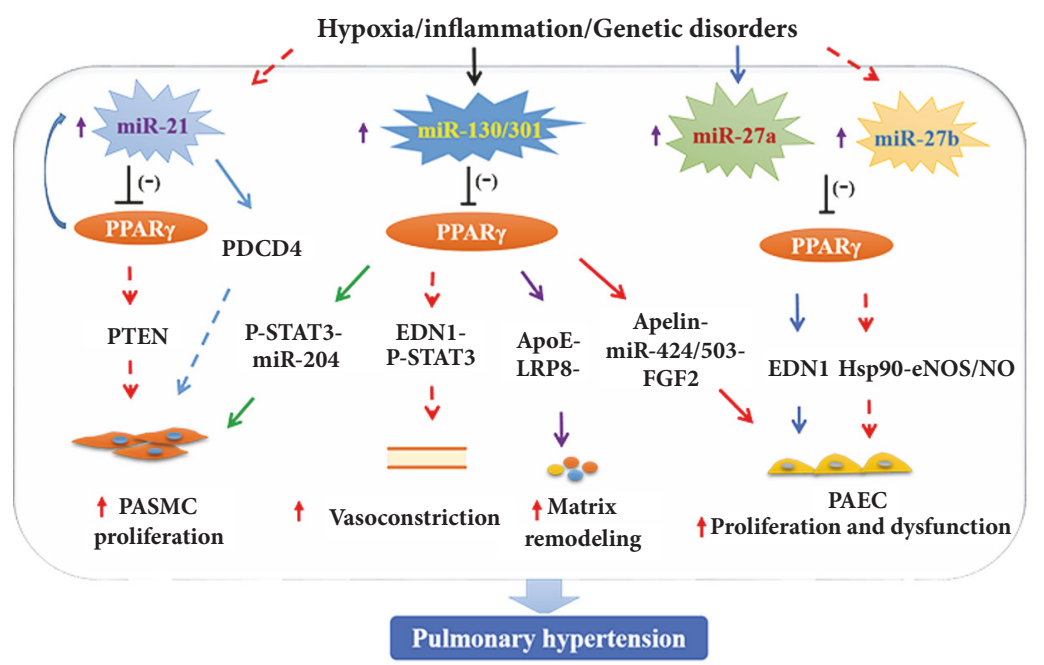

FIGURE 1: The regulation of peroxisome proliferator-activated receptors (PPARs) by microRNAs in pulmonary hypertension. PASMC: pulmonary arterial smooth muscle cells; PAEC: pulmonary arterial endothelial cells; PTEN: phosphatase and tensin homolog deleted on chromosome 10; PDCD4: programmed cell death 4; STAT3: signal transducer and activator of transcription 3; EDN1: endothelin-1; APOE: apolipoprotein E; NO: nitric oxide; eNOS: EC nitric oxide synthase.

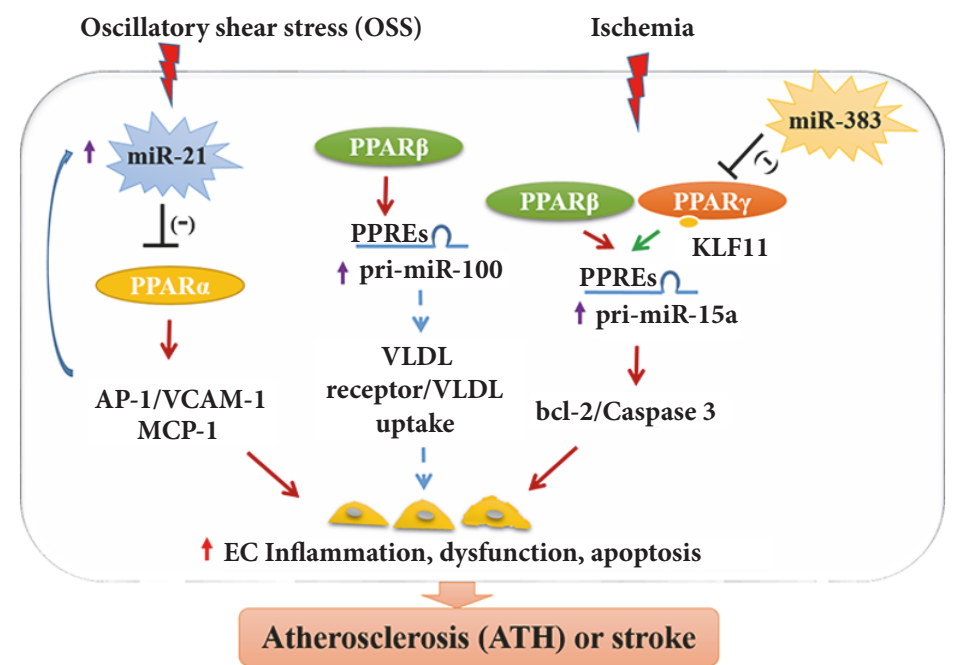

FIGURE 2: The regulatory function of microRNAs/peroxisome proliferator-activated receptors (PPARs) axis in the pathophysiology of atherosclerosis and stroke. EC: endothelial cell; AP-1: transcription factor activator protein-1; VCAM-1: vascular cell adhesion molecule-1; MCP-1: monocyte chemotactic protein-1; VLDL: very low-density lipoprotein; KLF11: Kruppel like factor 11.

cerebral ischemia. Upregulation of $\mathrm{PPAR} \beta / \delta$ could alleviate oxygen glucose deprivation-activated miRNA-15a transcription in CECs. In addition, miRNA-15a could directly inhibit the translation of Bcl-2 (Figure 2). PPAR $\beta / \delta$ agonist obviously decreased ischemia-induced transcripts of miRNA$15 \mathrm{a}$, promoted protein levels of $\mathrm{Bcl}-2$, and reduced caspase3 activity. Gain or loss of miRNA-15a function obviously reduced or increased OGD-activated CEC death, respectively [84]. Yin et al. further demonstrated that KLF11, a novel $\operatorname{PPAR} \gamma$ coregulator, interacted with $\operatorname{PPAR} \gamma$ and suppressed miRNA-15a, leading to endothelial protection both in CEC cultures and cerebral microvasculature following ischemic stimuli [85]. Additionally, miRNA-383 could contribute to focal cerebral ischemia through modulating PPAR $\gamma$ transcription at the posttranscriptional level in vitro and in vivo [86]. MiRNA-383 and PPAR $\gamma$ might serve as potential therapeutic strategies for stroke.

1.3.3. Heart Diseases. CVDs caused the leading death in patients with chronic kidney disease [87, 88]. $\operatorname{PPAR} \alpha$, a primary PPAR isoform in the heart, was shown to be a direct target of miRNA-21-5p (Figure 3). Suppression of miRNA-21$5 p$ could alter gene expression in PPAR $\alpha$ modulated pathways in the left ventricle. Moreover, cardiac function and left ventricle dilation were improved by therapeutic delivery of low-dose PPAR $\alpha$ agonist in rats with 5/6 nephrectomy [89]. 


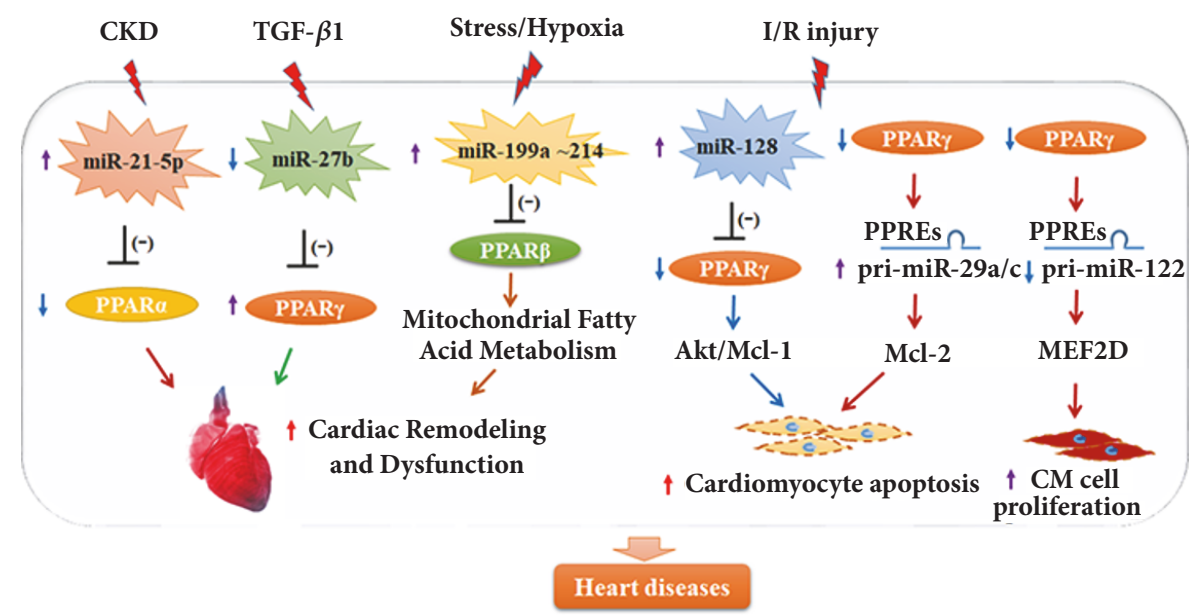

FIgURE 3: The regulatory function of microRNAs/peroxisome proliferator-activated receptors (PPARs) axis in cardiomyocyte apoptosis, and cardiac remodeling and dysfunction. CKD: chronic kidney disease; TGF- $\beta 1$ : transforming growth factor $\beta 1 ; 1 / R$ : ischemia/reperfusion; Akt: serine/threonine kinase 1; Mcl-1: myeloid leukaemia cell differentiation protein-1; Mcl-2: an anti-apoptotic Bcl-2 family member; MEF2D: myocyte enhancer factor 2D. CM: cardiac myxoma.

Cardiac injury is associated with marked induction of TGF- $\beta$, and the miRNA-27b expression was shown to be suppressed by TGF- $\beta 1$ in vitro. MiRNA-27b overexpression was sufficient to induce cardiac hypertrophy and dysfunction in vitro and in vivo. Furthermore, PPAR $\gamma$ was confirmed as a direct target of miRNA-27b in cardiomyocytes (Figure 3) [90].

In vitro, miRNA-128 suppression enhanced the activation of Akt (phosphorylated [p]-Akt), myeloid leukaemia cell differentiation protein-1 (Mcl-1), and PPAR $\gamma$ expression in the myocardium. MiRNA-128 suppression further attenuated cardiomyocyte apoptosis induced by myocardial I/R injury. The effects induced by miRNA-128 inhibition could be improved by the directly targeted activation of PPAR $\gamma$ (Figure 3) [91].

Pioglitazone (PIO), a PPAR $\gamma$ agonist, has been shown to prevent myocardial I/R injury. PIO treatment could directly decrease miRNA-29a and miRNA-29c agonist expression levels and promote the transcription of $\mathrm{Mcl}-2$, an antiapoptotic Bcl-2 family member (Figure 3) [92]. Thus, inhibition of miRNA-29 by targeting enhanced PPAR $\gamma$ showed an antiapoptotic effect, which protected the heart against I/R injury [92].

Several studies showed that abnormalities in energy production and cardiac lipid homeostasis were closely related to $\mathrm{HF}$. Under hemodynamic stress, $\operatorname{PPAR} \beta / \delta$, the crucial regulator of the energy metabolism of the heart, could be directly regulated by cardiac hypoxia that activates the microRNA cluster miRNA-199a-214. Moreover, miRNA-214 silencing enhanced cardiac contractility and improved mitochondrial FAO by inhibiting PPAR $\beta / \delta$ (Figure 3) [93].

Furthermore, the PPAR/miRNA axis was shown to be a crucial regulator of cardiac myxoma (CM), a predominant cardiac tumour especially in the young [94]. Activation of PPAR $\gamma$ could directly regulate miRNA-122 by binding to the PPRE in the promoter region and inhibit myocyte enhancer factor 2D (MEF2D) expression, an important biomarker of CM (Figure 3) [95]. Further experiments demonstrated that the decrease of MEF2D regulated by miR-122/PPAR $\gamma$ axis inhibited CM cell proliferation. These results suggest that the PPAR $\gamma /$ miRNA-122 signalling pathway might serve as a novel target to treat CM.

1.3.4. Obesity-Associated Cardiovascular Risks. Several miRNAs play vital roles in antiobesity by suppressing the expression of $\operatorname{PPAR} \gamma$, which regulates lipogenesis and adipogenesis. MiRNA-130 has been shown to reduce adipogenesis by repressing PPAR $\gamma$ (Figure 4) [96]. In addition, the fat deposition in recipient primary-cultured porcine adipocytes could be decreased by microvesicle-shuttled miRNA-130b through inhibiting PPAR $\gamma$ [97]. In a preadipocyte cell line 3T3-L1, miRNA-301a could modulate adipocyte dysfunction via directly suppressing PPAR $\gamma$ during obesity-related inflammation [98]. Procyanidins could promote lipolysis on adipose metabolism; grape seed procyanidin B2 was shown to inhibit adipogenesis in 3T3-L1 cells by regulating the miRNA483-5p/PPAR $\gamma$ signalling pathway [99]. A Chinese medicine, Astragalus polysaccharides, could attenuate $\mathrm{TNF} \alpha$-induced insulin resistance by inhibiting miRNA-721 expression, activating PPAR $\gamma$, and enhancing PI3K/Akt signalling in 3T3-L1 adipocytes (Figure 4) [100]. MiRNA-27b was shown to exert an antiadipogenic effect on human multipotent adiposederived stem cells by directly inhibiting PPAR $\gamma$ and another regulator of adipogenesis, $\mathrm{C} / \mathrm{EBP} \alpha$, at early onset of adipogenesis. Further, overexpression of miRNA-27b could suppress expression of the adipogenic marker gene and TG accumulation during the late stages of adipogenesis [101].

Polarized activation of adipose tissue macrophages is crucial to maintain normal adipose tissue function and mediate obesity-associated cardiovascular risk and metabolic abnormalities [102]. The PPAR $\gamma /$ miRNA-223 regulatory axis modulated macrophage polarization by regulating expression 


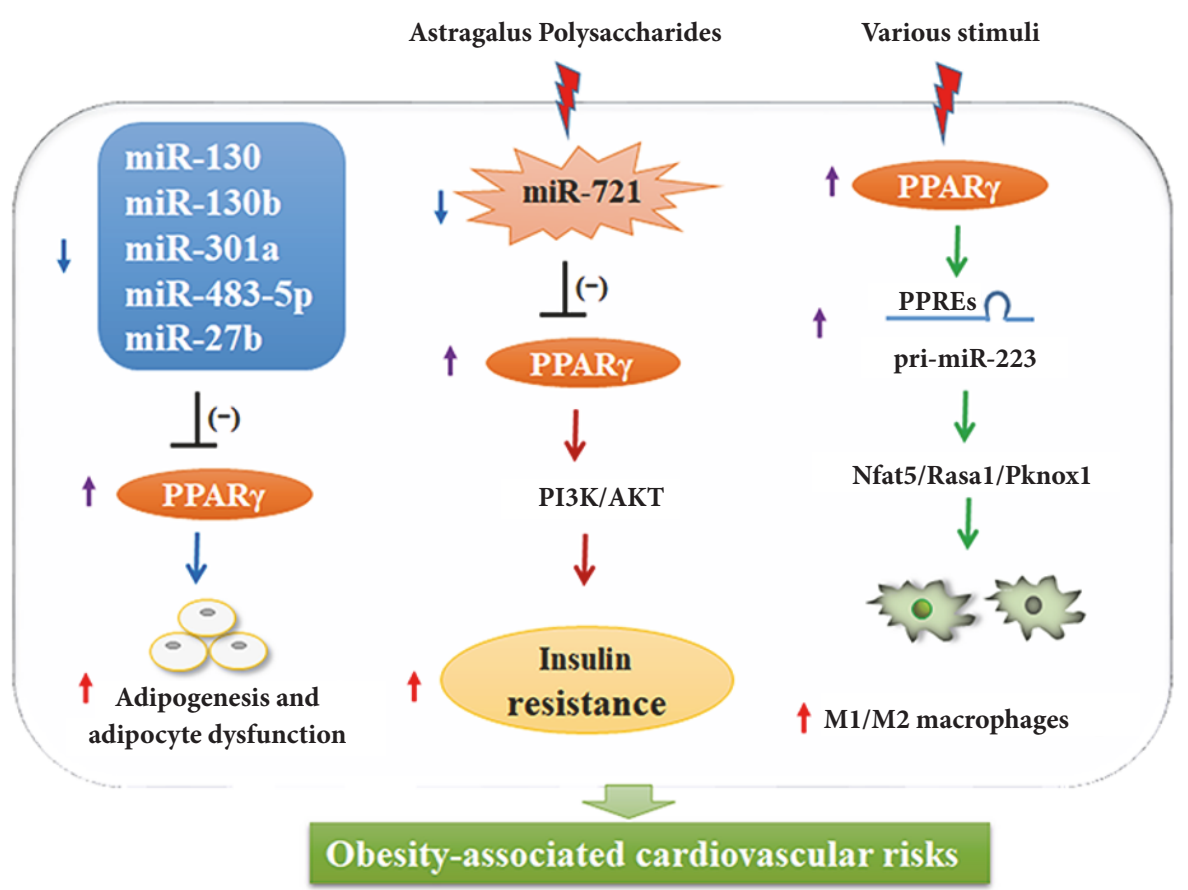

FIGURE 4: The regulatory function of microRNAs/peroxisome proliferator-activated receptors (PPARs) axis in obesity-associated cardiovascular risks. PI3K: phosphatidylinositol-4,5-bisphosphate 3-kinase; Akt: serine/threonine kinase 1; Nfat5: nuclear factor of activated T-cells 5; Rasa1: RAS p21 protein activator 1; Pknox1: Pbx/knotted 1 homeobox 1; M1/M2 macrophage: proinflammatory M1 macrophage /anti-inflammatory M2 macrophage.

of distinct downstream genes under various stimuli (Figure 4) [103]. In BM-derived macrophages, miRNA-223 transcription was directly promoted by PPAR $\gamma$ under Th2 stimuli, and Rasal (a member of the nuclear factors of the activated T-cells family of transcription factors), Nfat5 (a member of the GAP1 family of GTPase-activating proteins), and the proinflammatory regulator Pknoxl were identified as miRNA-223 targets. These findings further supported the theory that the mutual regulation of miRNAs and PPAR signalling might be a novel target for alleviating obesityassociated cardiovascular risks.

\section{Conclusion}

PPARs have a wide spectrum of biological activities relevant to the prevention and treatment of CVDs, including regulating energy homeostasis, promoting proliferation, and inhibiting inflammation, oxidative stress, and apoptosis in vascular cells, cardiomyocytes, and adipocytes. Increasing evidence suggests that miRNAs serve as key mediators of pathogenesis in CVDs and their risks. However, the important and versatile regulatory function of the interaction of PPARs and miRNAs has not been studied extensively. This review stated that PPARs can be inhibited through posttranscriptional mechanisms that involve miRNAs in the progress of $\mathrm{PH}$, vascular dysfunction, heart diseases, and obesity-related CVD risks. In addition, the ability of PPARs to change the posttranscriptional expression of target miRNAs through miRNA signalling in the CVD pathophysiology was also discussed. This indicates that strategies targeting PPAR can regulate not only transcriptional but also posttranscriptional regulation of cardiac and vasoactive mediators to favourably modulate CVD pathogenesis. In conclusion, the review illustrated a direct link between miRNAs and nuclear receptor PPARs in the context of $\mathrm{PH}$, vascular dysfunction, heart diseases, and obesity-related cardiovascular risks and demonstrated that targeting the miRNA/PPAR axis may represent a novel therapeutic approach for CVDs.

\section{Conflicts of Interest}

All the authors declared no conflicts of interest.

\section{Acknowledgments}

This work was supported by grants from the Shandong Provincial Natural Science Foundation of China (ZR2016BB32), China Postdoctoral Science Foundation Funded Project (2016M600520), the State Key Laboratory of Environmental Chemistry and Ecotoxicology, Research Center for Eco-Environmental Sciences, Chinese Academy of Sciences (KF2016-23), and Top Discipline of Public Health and Prevent Medicine (NXYLXK2017B08), Education Department of Ningxia, China.

\section{References}

[1] A. R. Majithia, B. Tsuda, M. Agostini et al., "Prospective functional classification of all possible missense variants in PPARG," Nature Genetics, vol. 48, no. 12, pp. 1570-1575, 2016. 
[2] V. Dubois, J. Eeckhoute, P. Lefebvre, and B. Staels, "Distinct but complementary contributions of PPAR isotypes to energy homeostasis," The Journal of Clinical Investigation, vol. 127, no. 4, pp. 1202-1214, 2017.

[3] J. G. Neels and P. A. Grimaldi, "Physiological functions of peroxisome proliferator-activated receptor $\beta$," Physiological Reviews, vol. 94, no. 3, pp. 795-858, 2014.

[4] A. N. Orekhov, N. Mukhamedova, E. A. Ivanova, and M. Rizzo, "PPAR in Cardiovascular Disorders," PPAR Research, vol. 2016, 2016.

[5] F. Hong, P. Xu, and Y. Zhai, “The Opportunities and Challenges of Peroxisome Proliferator-Activated Receptors Ligands in Clinical Drug Discovery and Development," International Journal of Molecular Sciences, vol. 19, no. 8, p. 2189, 2018.

[6] S. Yousefnia, S. Momenzadeh, F. Seyed Forootan, K. Ghaedi, and M. H. Nasr Esfahani, "The influence of peroxisome proliferator-activated receptor $\gamma(\operatorname{PPAR} \gamma)$ ligands on cancer cell tumorigenicity," Gene, vol. 649, pp. 14-22, 2018.

[7] P. Lacolley, V. Regnault, P. Segers, and S. Laurent, "Vascular smooth muscle cells and arterial stiffening: Relevance in development, aging, and disease," Physiological Reviews, vol. 97, no. 4, pp. 1555-1617, 2017.

[8] J. Lauriol, J. R. Cabrera, A. Roy et al., "Developmental SHP2 dysfunction underlies cardiac hypertrophy in Noonan syndrome with multiple lentigines," The Journal of Clinical Investigation, vol. 126, no. 8, pp. 2989-3005, 2016.

[9] K. Wang, T.-Y. Gan, N. Li et al., "Circular RNA mediates cardiomyocyte death via miRNA-dependent upregulation of MTP18 expression," Cell Death \& Differentiation, vol. 24, no. 6, pp. 11111120, 2017.

[10] M. Nahrendorf, "Myeloid cell contributions to cardiovascular health and disease," Nature Medicine, vol. 24, no. 6, pp. 711-720, 2018.

[11] S. E. Simonds, J. T. Pryor, E. Ravussin et al., "Leptin mediates the increase in blood pressure associated with obesity," Cell, vol. 159, no. 6, pp. 1404-1416, 2014.

[12] C. Luo, N. Lv, Z. Chang, Q. Qu, and J. Huang, "Adipose angiotensin II type 1 receptor-associated protein ameliorates metabolic disorders via promoting adipose tissue adipogenesis and browning," European Journal of Cell Biology, vol. 96, no. 6, pp. 567-578, 2017.

[13] A. Schober and C. Weber, "Mechanisms of MicroRNAs in Atherosclerosis," Annual Review of Pathology: Mechanisms of Disease, vol. 11, pp. 583-616, 2016.

[14] D. Yao, L. Xu, O. Xu et al., "O-Linked $\beta$-N-Acetylglucosamine Modification of A20 Enhances the Inhibition of NF- $\kappa$ B (Nuclear Factor- $\kappa \mathrm{B}$ ) Activation and Elicits Vascular Protection After Acute Endoluminal Arterial Injury," Arteriosclerosis, Thrombosis, and Vascular Biology, vol. 38, no. 6, pp. 1309-1320, 2018.

[15] Y. Cai, D. J. Nagel, Q. Zhou et al., "Role of cAMP-phosphodiesterase $1 \mathrm{C}$ signaling in regulating growth factor receptor stability, vascular smooth muscle cell growth, migration, and neointimal hyperplasia," Circulation Research, vol. 116, no. 7, pp. 1120-1132, 2015.

[16] L. Zhao, E. Oliver, K. Maratou et al., "The zinc transporter ZIP12 regulates the pulmonary vascular response to chronic hypoxia," Nature, vol. 524, no. 7565, pp. 356-360, 2015.

[17] A. A. R. Thompson and A. Lawrie, "Targeting Vascular Remodeling to Treat Pulmonary Arterial Hypertension," Trends in Molecular Medicine, vol. 23, no. 1, pp. 31-45, 2017.
[18] D. Auboeuf, J. Rieusset, L. Fajas et al., "Tissue distribution and quantification of the expression of mRNAs of peroxisome proliferator-activated receptors and liver X receptor- $\alpha$ in humans: no alteration in adipose tissue of obese and NIDDM patients," Diabetes, vol. 46, no. 8, pp. 1319-1327, 1997.

[19] D. Guan, Y. Xiong, P. C. Borck et al., "Diet-Induced Circadian Enhancer Remodeling Synchronizes Opposing Hepatic Lipid Metabolic Processes," Cell, vol. 174, no. 4, pp. 831-842.e12, 2018.

[20] G. A. Preidis, K. H. Kim, and D. D. Moore, "Nutrient-sensing nuclear receptors PPAR? and FXR control liver energy balance," The Journal of Clinical Investigation, vol. 127, no. 4, pp. 1193-1201, 2017.

[21] E. Czarnowska, D. Domal-Kwiatkowska, E. ReichmanWarmusz et al., "The correlation of PPAR $\alpha$ activity and cardiomyocyte metabolism and structure in idiopathic dilated cardiomyopathy during heart failure progression," PPAR Research, vol. 2016, 2016.

[22] N. D. Roe, S. W. Standage, and R. Tian, "The Relationship between KLF5 and PPAR $\alpha$ in the Heart: It's Complicated," Circulation Research, vol. 118, no. 2, pp. 193-195, 2016.

[23] L. Han, W.-J. Shen, S. Bittner, F. B. Kraemer, and S. Azhar, "PPARs: Regulators of metabolism and as therapeutic targets in cardiovascular disease. Part I: PPAR- $\alpha$," Future Cardiology, vol. 13, no. 3, pp. 259-278, 2017.

[24] S. Lahnwong, S. C. Chattipakorn, and N. Chattipakorn, "Potential mechanisms responsible for cardioprotective effects of sodium-glucose co-transporter 2 inhibitors," Cardiovascular Diabetology, vol. 17, no. 1, 2018.

[25] N. Bougarne, B. Weyers, S. J. Desmet et al., "Molecular Actions of PPAR $\alpha$ in Lipid Metabolism and Inflammation," Endocrine Reviews, vol. 39, no. 5, pp. 760-802, 2018.

[26] D. M. Herrington, C. Mao, S. J. Parker et al., "Proteomic Architecture of Human Coronary and Aortic Atherosclerosis," Circulation, vol. 137, no. 25, pp. 2741-2756, 2018.

[27] A. Roy, M. Kundu, M. Jana et al., "Identification and characterization of PPAR $\alpha$ ligands in the hippocampus," Nature Chemical Biology, vol. 12, no. 12, pp. 1075-1083, 2016.

[28] A. Iroz, A. Montagner, F. Benhamed et al., "A Specific ChREBP and PPAR $\alpha$ Cross-Talk Is Required for the Glucose-Mediated FGF21 Response," Cell Reports, vol. 21, no. 2, pp. 403-416, 2017.

[29] J. A. Horscroft, A. O. Kotwica, V. Laner et al., "Metabolic basis to sherpa altitude adaptation," Proceedings of the National Acadamy of Sciences of the United States of America, vol. 114, no. 24, pp. 6382-6387, 2017.

[30] G. Derosa, A. Sahebkar, and P. Maffioli, "The role of various peroxisome proliferator-activated receptors and their ligands in clinical practice," Journal of Cellular Physiology, vol. 233, no. 1, pp. 153-161, 2018.

[31] S. Pontis, A. Ribeiro, O. Sasso, and D. Piomelli, "Macrophagederived lipid agonists of PPAR- $\alpha$ as intrinsic controllers of inflammation," Critical Reviews in Biochemistry and Molecular Biology, vol. 51, no. 1, pp. 7-14, 2016.

[32] K. Drosatos, N. M. Pollak, C. J. Pol et al., "Cardiac myocyte KLF5 regulates Ppara expression and cardiac function," Circulation Research, vol. 118, no. 2, pp. 241-253, 2016.

[33] D. Duteil, M. Tosic, D. Willmann, A. Georgiadi, T. Kanouni, and R. Schüle, "Lsdl prevents age-programed loss of beige adipocytes," Proceedings of the National Acadamy of Sciences of the United States of America, vol. 114, no. 20, pp. 5265-5270, 2017.

[34] T. Goto, J.-Y. Lee, A. Teraminami et al., "Activation of peroxisome proliferator-activated receptor-alpha stimulates both 
differentiation and fatty acid oxidation in adipocytes," Journal of Lipid Research, vol. 52, no. 5, pp. 873-884, 2011.

[35] J.-H. Koh, C. R. Hancock, S. Terada, K. Higashida, J. O. Holloszy, and D.-H. Han, "PPAR $\beta$ Is Essential for Maintaining Normal Levels of PGC- $1 \alpha$ and Mitochondria and for the Increase in Muscle Mitochondria Induced by Exercise," Cell Metabolism, vol. 25, no. 5, pp. 1176-1185.e5, 2017.

[36] P. Luz-Crawford, N. Ipseiz, G. Espinosa-Carrasco et al., "PPAR $\beta / \delta$ directs the therapeutic potential of mesenchymal stem cells in arthritis," Annals of the Rheumatic Diseases, 2016.

[37] Y. Ding, K. D. Yang, and Q. Yang, “The role of PPAR $\delta$ signaling in the cardiovascular system," Progress in Molecular Biology and Translational Science, vol. 121, pp. 451-473, 2014.

[38] N. S. Tan, M. Vázquez-Carrera, A. Montagner, M. K. Sng, H. Guillou, and W. Wahli, "Transcriptional control of physiological and pathological processes by the nuclear receptor PPAR $\beta / \delta$," Progress in Lipid Research, vol. 64, pp. 98-122, 2016.

[39] J. M. Peters, F. J. Gonzalez, and R. Müller, "Establishing the Role of PPAR $\beta / \delta$ in Carcinogenesis," Trends in Endocrinology \& Metabolism, vol. 26, no. 11, pp. 595-607, 2015.

[40] M. Vázquez-Carrera, "Unraveling the effects of $\operatorname{PPAR} \beta / \delta$ on insulin resistance and cardiovascular disease," Trends in Endocrinology \& Metabolism, vol. 27, no. 5, pp. 319-334, 2016.

[41] T. Adhikary, A. Wortmann, T. Schumann et al., "The transcriptional PPAR $\beta / \delta$ network in human macrophages defines a unique agonist-induced activation state," Nucleic Acids Research, vol. 43, no. 10, pp. 5033-5051, 2015.

[42] M. Mansour, “The roles of peroxisome proliferator-activated receptors in the metabolic syndrome," in Progress in Molecular Biology and Translational Science, vol. 121, chapter 7, pp. 217266, Elsevier, 2014.

[43] Wang-Soo Lee and Jaetaek Kim, "Peroxisome ProliferatorActivated Receptors and the Heart: Lessons from the Past and Future Directions," PPAR Research, vol. 2015, Article ID 271983, 18 pages, 2015.

[44] K.-D. Wagner, A. Vukolic, D. Baudouy, J.-F. Michiels, and N. Wagner, "Inducible conditional vascular-specific overexpression of peroxisome proliferator-activated receptor beta/delta leads to rapid cardiac hypertrophy," PPAR Research, vol. 2016, Article ID 7631085, 12 pages, 2016.

[45] L. Schirone, M. Forte, S. Palmerio et al., "A Review of the Molecular Mechanisms Underlying the Development and Progression of Cardiac Remodeling," Oxidative Medicine and Cellular Longevity, vol. 2017, 2017.

[46] M. Leone, A. Magadum, and F. B. Engel, "Cardiomyocyte proliferation in cardiac development and regeneration: A guide to methodologies and interpretations," American Journal of Physiology-Heart and Circulatory Physiology, vol. 309, no. 8, pp. H1237-H1250, 2015.

[47] A. Magadum, Y. Ding, L. He et al., "Live cell screening platform identifies PPAR $\delta$ as a regulator of cardiomyocyte proliferation and cardiac repair," Cell Research, vol. 27, no. 8, pp. 1002-1019, 2017.

[48] R. E. Soccio, E. R. Chen, S. R. Rajapurkar et al., "Genetic variation determines PPAR $\gamma$ function and anti-diabetic drug response in vivo," Cell, vol. 162, no. 1, pp. 33-44, 2015.

[49] L. Z. Agudelo, T. Femenía, F. Orhan et al., "Erratum:Skeletal muscle PGC- $1 \alpha 1$ modulates kynurenine metabolism and mediates resilience to stress-induced depression (Cell (2014) 159 (3345))," Cell, vol. 160, no. 1-2, p. 351, 2015.
[50] Y. Niu, B. Shen, Y. Cui et al., "Generation of gene-modified cynomolgus monkey via Cas9/RNA-mediated gene targeting in one-cell embryos," Cell, vol. 156, no. 4, pp. 836-843, 2014.

[51] P. A. Dutchak, T. Katafuchi, A. L. Bookout et al., "Fibroblast growth factor- 21 regulates PPAR $\gamma$ activity and the antidiabetic actions of thiazolidinediones," Cell, vol. 148, no. 3, pp. 556-567, 2012.

[52] Y. Zhang, O. S. Dallner, T. Nakadai et al., "A noncanonical $\operatorname{PPAR} \gamma / \mathrm{RXR} \alpha$-binding sequence regulates leptin expression in response to changes in adipose tissue mass," Proceedings of the National Acadamy of Sciences of the United States of America, vol. 115, no. 26, pp. E6039-E6047, 2018.

[53] J. H. Choi, A. S. Banks, J. L. Estall et al., "Anti-diabetic drugs inhibit obesity-linked phosphorylation of PPAR $\gamma 3$ by Cdk5," Nature, vol. 466, no. 7305, pp. 451-456, 2010.

[54] C. Guo, A. M. D’Ippolito, and T. E. Reddy, "From Prescription to Transcription: Genome Sequence as Drug Target," Cell, vol. 162, no. 1, pp. 16-17, 2015.

[55] J. V. Huang, C. R. Greyson, and G. G. Schwartz, "PPAR- $\gamma$ as a therapeutic target in cardiovascular disease: evidence and uncertainty," Journal of Lipid Research, vol. 53, no. 9, pp. 1738$1754,2012$.

[56] K. L. Eckel-Mahan, V. R. Patel, S. De Mateo et al., "Reprogramming of the circadian clock by nutritional challenge," Cell, vol. 155, no. 7, pp. 1464-1478, 2013.

[57] M. Chandra, S. Miriyala, and M. Panchatcharam, "PPAR $\gamma$ and Its Role in Cardiovascular Diseases," PPAR Research, vol. 2017, 2017.

[58] K. Kim, K. Boo, Y. S. Yu et al., "ROR $\alpha$ controls hepatic lipid homeostasis via negative regulation of PPAR $\gamma$ transcriptional network," Nature Communications, vol. 8, no. 1, article no. 162, 2017.

[59] D. Lasar, M. Rosenwald, E. Kiehlmann et al., "Peroxisome Proliferator Activated Receptor Gamma Controls Mature Brown Adipocyte Inducibility through Glycerol Kinase," Cell Reports, vol. 22, no. 3, pp. 760-773, 2018.

[60] V. L. Nelson, H. C. Nguyen, J. C. Garcìa-Cañaveras et al., "PPAR $\gamma$ is a nexus controlling alternative activation of macrophages via glutamine metabolism," Genes \& Development, vol. 32, no. 15-16, pp. 1035-1044, 2018.

[61] R. C. Lee, R. L. Feinbaum, and V. Ambros, "The C. elegans heterochronic gene lin-4 encodes small RNAs with antisense complementarity to lin-14," Cell, vol. 75, no. 5, pp. 843-854, 1993.

[62] S. L. Ameres and P. D. Zamore, "Diversifying microRNA sequence and function," Nature Reviews Molecular Cell Biology, vol. 14, no. 8, pp. 475-488, 2013.

[63] D. P. Bartel, "Metazoan MicroRNAs," Cell, vol.173, no. 1, pp. 20 51, 2018.

[64] D. P. Bartel, "MicroRNAs: target recognition and regulatory functions," Cell, vol. 136, no. 2, pp. 215-233, 2009.

[65] M. Ha and V. N. Kim, "Regulation of microRNA biogenesis," Nature Reviews Molecular Cell Biology, vol. 15, pp. 509-524, 2014.

[66] V. Rottiers and A. M. Näär, "MicroRNAs in metabolism and metabolic disorders," Nature Reviews Molecular Cell Biology, vol. 13, no. 4, pp. 239-250, 2012.

[67] T. Desvignes, P. Batzel, E. Berezikov et al., "MiRNA Nomenclature: A View Incorporating Genetic Origins, Biosynthetic Pathways, and Sequence Variants," Trends in Genetics, vol. 31, no. 11, pp. 613-626, 2015. 
[68] Y. Xia, R. Zhang, Z. Wang, J. Tian, and X. Chen, "Recent advances in high-performance fluorescent and bioluminescent RNA imaging probes," Chemical Society Reviews, vol. 46, no. 10, pp. 2824-2843, 2017.

[69] M. W. Feinberg and K. J. Moore, "MicroRNA regulation of atherosclerosis," Circulation Research, vol. 118, no. 4, pp. 703720, 2016.

[70] P. Gurha, "MicroRNAs in cardiovascular disease," Current Opinion in Cardiology, vol. 31, no. 3, pp. 249-254, 2016.

[71] S. Samanta, S. Balasubramanian, S. Rajasingh et al., "MicroRNA: A new therapeutic strategy for cardiovascular diseases," Trends in Cardiovascular Medicine, vol. 26, no. 5, pp. 407-419, 2016.

[72] J.-X. Wang, X.-J. Zhang, Q. Li et al., "MicroRNA-103/107 regulate programmed necrosis and myocardial ischemia/reperfusion injury through targeting FADD," Circulation Research, vol. 117, no. 4, pp. 352-363, 2015.

[73] T. Bertero, K. Cottrill, A. Krauszman et al., "The microRNA130/301 family controls vasoconstriction in pulmonary hypertension," The Journal of Biological Chemistry, vol. 290, no. 4, pp. 2069-2085, 2015.

[74] T. Bertero, K. A. Cottrill, Y. Lu et al., "Matrix Remodeling Promotes Pulmonary Hypertension through Feedback Mechanoactivation of the YAP/TAZ-miR-130/301 Circuit," Cell Reports, vol. 13, no. 5, pp. 1016-1032, 2015.

[75] T. Bertero, Y. Lu, and S. Annis, "Systems-level regulation of microRNA networks by miR-130/301 promotes pulmonary hypertension," The Journal of Clinical Investigation, vol. 124, no. 8, pp. 3514-3528, 2014.

[76] B.-Y. Kang, K. K. Park, D. E. Green et al., "Hypoxia mediates mutual repression between microRNA-27a and PPAR $\gamma$ in the pulmonary vasculature," PLOS ONE, vol. 8, no. 11, Article ID e79503, 2013.

[77] R. Bi, C. Bao, L. Jiang et al., "MicroRNA-27b plays a role in pulmonary arterial hypertension by modulating peroxisome proliferator-activated receptor $\gamma$ dependent Hsp90-eNOS signaling and nitric oxide production," Biochemical and Biophysical Research Communications, vol. 460, no. 2, pp. 469-475, 2015.

[78] D. E. Green, T. C. Murphy, B. Kang, C. D. Searles, C. M. Hart, and J. West, "PPAR $\gamma$ Ligands Attenuate Hypoxia-Induced Proliferation in Human Pulmonary Artery Smooth Muscle Cells through Modulation of MicroRNA-21," PLoS ONE, vol. 10, no. 7, p. e0133391, 2015.

[79] D. E. Green, T. C. Murphy, B.-Y. Kang et al., "Peroxisome proliferator-activated receptor- $\gamma$ enhances human pulmonary artery smooth muscle cell apoptosis through microRNA-21 and programmed cell death 4," American Journal of Physiology-Lung Cellular and Molecular Physiology, vol. 313, no. 2, pp. L371-L383, 2017.

[80] I. Tabas and A. H. Lichtman, "Monocyte-Macrophages and T Cells in Atherosclerosis," Immunity, vol. 47, no. 4, pp. 621-634, 2017.

[81] J. Zhou, K.-C. Wang, W. Wu et al., "MicroRNA-21 targets peroxisome proliferators-activated receptor- $\alpha$ in an autoregulatory loop to modulate flow-induced endothelial inflammation," Proceedings of the National Acadamy of Sciences of the United States of America, vol. 108, no. 25, pp. 10355-10360, 2011.

[82] N. G. Seidah, M. Abifadel, S. Prost, C. Boileau, and A. Prat, “The proprotein convertases in hypercholesterolemia and cardiovascular diseases: Emphasis on proprotein convertase subtilisin/Kexin 9," Pharmacological Reviews, vol. 69, no. 1, pp. 33-52, 2017.
[83] X. Fang, L. Fang, A. Liu, X. Wang, B. Zhao, and N. Wang, "Activation of PPAR-delta induces microRNA-100 and decreases the uptake of very low-density lipoprotein in endothelial cells," British Journal of Pharmacology, vol. 172, no. 15, pp. 3728-3736, 2015.

[84] A. K. Sarda, S. Bal, Arunabh, M. K. Singh, and M. M. Kapur, "Peroxisome proliferator-activated receptor $\delta$ regulation of miR-15a in ischemia-induced cerebral vascular endothelial injury," The Journal of Neuroscience, vol. 30, no. 18, pp. 63986408, 2010.

[85] K.-J. Yin, Y. Fan, M. Hamblin et al., "KLF11 mediates PPARgamma cerebrovascular protection in ischaemic stroke," Brain, vol. 136, no. 4, pp. 1274-1287, 2013.

[86] L. Pei, S. Meng, W. Yu, Q. Wang, F. Song, and L. Ma, "Inhibition of MicroRNA-383 Ameliorates Injury after Focal Cerebral Ischemia via Targeting PPAR $\gamma$," Cellular Physiology and Biochemistry, vol. 39, no. 4, pp. 1339-1346, 2016.

[87] X. Ma, Y. Ding, Y. Wang, and X. Xu, "A Doxorubicin-induced Cardiomyopathy Model in Adult Zebrafish," Journal of Visualized Experiments, no. 136, 2018.

[88] B. Zeng, G.-L. Chen, E. Garcia-Vaz et al., "Orai channels are critical for receptor-mediated endocytosis of albumin," Nature Communications, vol. 8, no. 1, 2017.

[89] S. Chuppa, M. Liang, P. Liu et al., "MicroRNA-21 regulates peroxisome proliferator-activated receptor alpha, a molecular mechanism of cardiac pathology in Cardiorenal Syndrome Type 4," Kidney International, vol. 93, no. 2, pp. 375-389, 2018.

[90] J. Wang, Y. Song, Y. Zhang et al., "Cardiomyocyte overexpression of miR-27b induces cardiac hypertrophy and dysfunction in mice," Cell Research, vol. 22, no. 3, pp. 516-527, 2012.

[91] X. C. Zeng, L. Li, H. Wen, and Q. Bi, "MicroRNA-128 inhibition attenuates myocardial ischemia/reperfusion injury-induced cardiomyocyte apoptosis by the targeted activation of peroxisome proliferator-activated receptor gamma," Molecular Medicine Reports, vol. 14, no. 1, pp. 129-136, 2016.

[92] Y. Ye, Z. Hu, Y. Lin, C. Zhang, and J. R. Perez-Polo, "Downregulation of microRNA-29 by antisense inhibitors and a PPAR$\gamma$ agonist protects against myocardial ischaemia-reperfusion injury," Cardiovascular Research, vol. 87, no. 3, pp. 535-544, 2010.

[93] H. El Azzouzi, S. Leptidis, E. Dirkx et al., “The hypoxiainducible microRNA cluster miR-199a approximately 214 targets myocardial PPARdelta and impairs mitochondrial fatty acid oxidation," Cell Metabolism, vol. 18, no. 3, pp. 341-354, 2013.

[94] D. F. Boyer, P. A. McKelvie, L. De Leval et al., "Fibrin-associated EBV-positive Large B-Cell Lymphoma: An Indolent Neoplasm with Features Distinct from Diffuse Large B-Cell Lymphoma Associated with Chronic Inflammation," The American Journal of Surgical Pathology, vol. 41, no. 3, pp. 299-312, 2017.

[95] Y. Qiu, J. Yang, S. Bian, G. Chen, and J. Yu, "PPAR $\gamma$ suppresses the proliferation of cardiac myxoma cells through downregulation of MEF2D in a MIR-122-dependent manner," Biochemical and Biophysical Research Communications, vol. 474, no. 3, pp. 560-565, 2016.

[96] E. K. Lee, M. J. Lee, K. Abdelmohsen et al., "miR-130 suppresses adipogenesis by inhibiting peroxisome proliferator-activated receptor $\gamma$ expression," Molecular and Cellular Biology, vol. 31, no. 4, pp. 626-638, 2011.

[97] S. Pan, X. Yang, Y. Jia, R. Li, and R. Zhao, "Microvesicle-shuttled miR-130b reduces fat deposition in recipient primary cultured porcine adipocytes by inhibiting PPAR- $\gamma$ expression," Journal of Cellular Physiology, vol. 229, no. 5, pp. 631-639, 2014. 
[98] H. Li, M. Xue, J. Xu, and X. Qin, "MiR-301a is involved in adipocyte dysfunction during obesity-related inflammation via suppression of PPAR $\gamma$," Pharmazie, vol. 71, pp. 84-88, 2016.

[99] J. Zhang, Y. Huang, H. Shao, Q. Bi, J. Chen, and Z. Ye, “Grape seed procyanidin B2 inhibits adipogenesis of 3T3-L1 cells by targeting peroxisome proliferator-activated receptor $\gamma$ with miR483-5p involved mechanism," Biomedicine \& Pharmacotherapy, vol. 86, pp. 292-296, 2017.

[100] B. Ke, X. Ke, X. Wan et al., "Astragalus polysaccharides attenuates TNF- $\alpha$-induced insulin resistance via suppression of miR-721 and activation of PPAR- $\gamma$ and PI3K/akt in 3T3-L1 adipocytes," American Journal of Translational Research, vol. 9, no. 5, pp. 2195-2206, 2017.

[101] M. Karbiener, C. Fischer, S. Nowitsch et al., "microRNA miR-27b impairs human adipocyte differentiation and targets PPAR $\gamma$, , Biochemical and Biophysical Research Communications, vol. 390, no. 2, pp. 247-251, 2009.

[102] W. Ying, M. Riopel, G. Bandyopadhyay et al., "Adipose Tissue Macrophage-Derived Exosomal miRNAs Can Modulate in Vivo and in Vitro Insulin Sensitivity," Cell, vol. 171, no. 2, pp. 372-384.e12, 2017.

[103] W. Ying, A. Tseng, R. C.-A. Chang et al., "MicroRNA-223 is a crucial mediator of PPAR $\gamma$-regulated alternative macrophage activation," The Journal of Clinical Investigation, vol. 125, no. 11, pp. 4149-4159, 2015. 


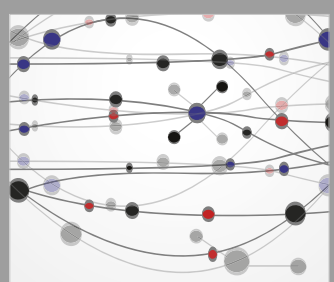

The Scientific World Journal
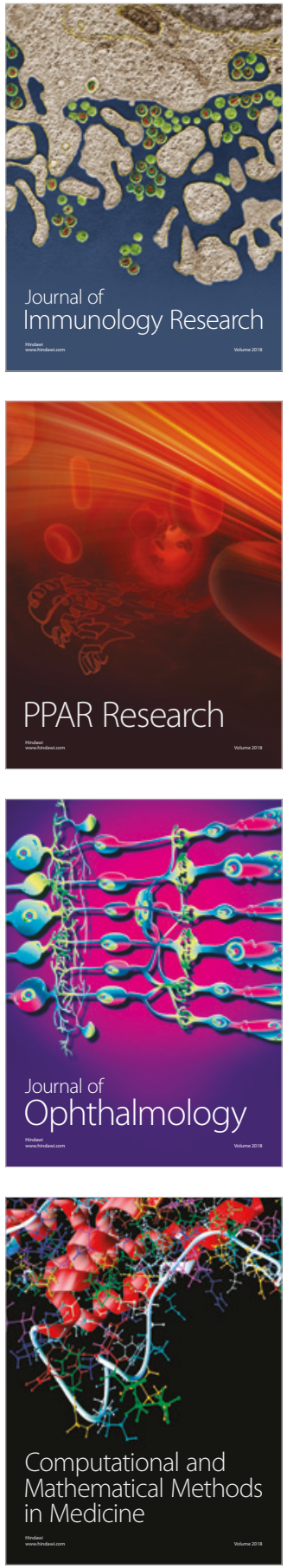

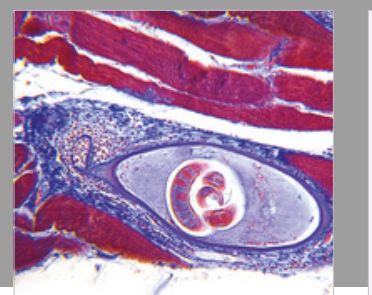

Gastroenterology Research and Practice

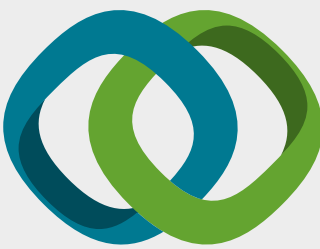

\section{Hindawi}

Submit your manuscripts at

www.hindawi.com
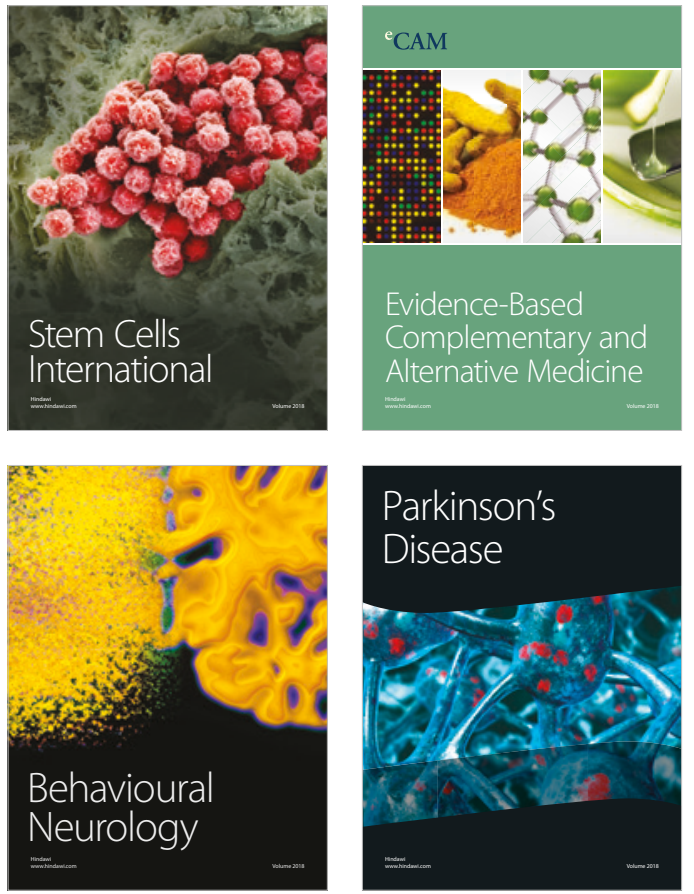

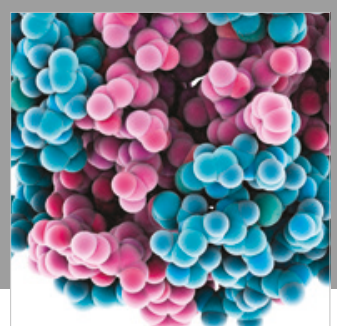

ournal of

Diabetes Research

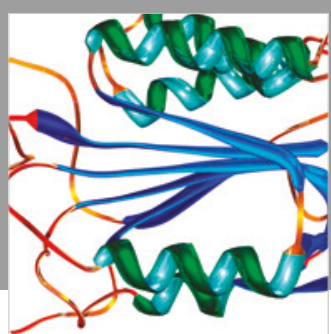

Disease Markers
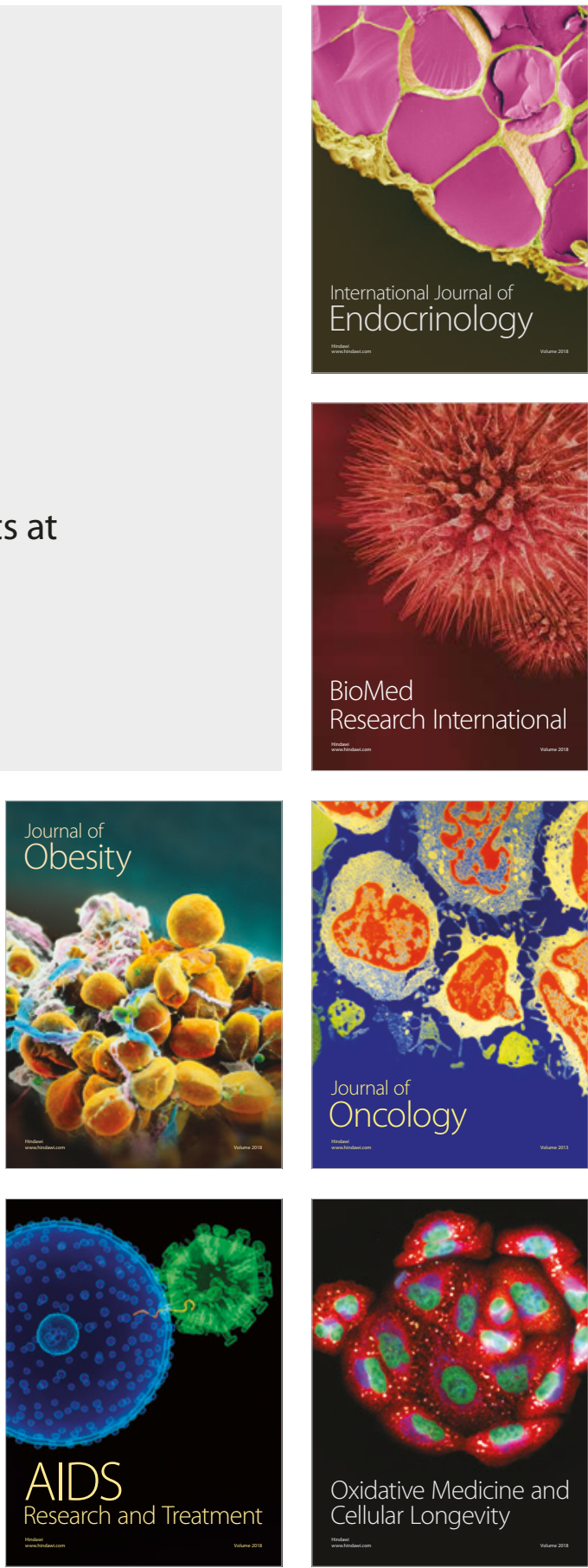